his collaborators, for the lower horizons from the Algonkian to the Ordovician in their whole extent. Slavík and Prof. Kettner completed in a series of publications the older research of Slavik on the Algonkian; Kettner worked up in monographs the lowest Cambrian (layers of Zitec) and the lower siluric horizon of Krušná Hora from the point of view of the genesis of the sediments; Dr. Slavík, with Mrs. Dr. Slavík, has described the oolitic chamoisite ores, their sedimentary genesis and the circulation of phosphorus.

Numerous other papers on the Barrandien by Kettner, Kodym, Purkyně, now director of our State Geological Institute, and Prof. Woldłich, give detailed tectonic pictures of the single districts; Kettner and Kodym have proposed a change of Barrande's designation of the horizons which is in agreement with the recent results of their investigation.

Another formation which is extended over large areas in Bohemia and Moravia and richly divided is the Cretaceous formation. The detailed stratigraphy and facial change of this formation has been for more than thirty years the object of thorough studies by Ceněk Zahálka, who has published great monographs of the Cretaceous formation in Podripsko, Středohor̀i and Eastern Bohemia, whereas the environments of Prague were in this direction investigated by his son, Bretislav Zahálka; special studies were made by Woldrich.

As regards the petrography and geology of plutonic eruptive rocks and crystalline schists, two territories were intensively studied within recent times: the Bohemian Forest and the granitic massive of Middle Bohemia.

The work of Sokol on the Bohemian Forest has yielded a basis for broader studies of the primary inhomogeneity of the magma.
The ore deposits were also intensely investigated, especially the gold-veins and beds of iron ores (Mrs. Dr. and Prof. Slavík, Kettner, Stočes).

In special mineralogy a series of crystallographic papers was published (Ježek on Johannite, Ondrej on the Bohemian quartzes, Rosický on the topaz and gypsum, slavík on the lacroisite), and chemical papers (Splíchal on the products of decomposition of the felspars, Rosický and Sterrba-Böhm on the ultrabasite)

GEOGRAPHY.-During the war this science centred round the " Bohemian Geographical Society," which, in spite of the difficult conditions, was able to issue its transactions in the "Sbornik." Owing to the Austrian censorship political geography was very limited and chiefly physical geography was cultivated. The fall of Austria means, of course, a new era for our political geography. Prof. Daneš's studies on the population of the industrial districts of Bohemia and Prof. Dvorský's on Yugoslavia as well as his book, with a political programme, on the territory of the Czechoslovak people, are the prominent works in this branch. A great work was started in ethnography with the first volume of the "Ethnography of the Czechoslovak People" (editor K. Chotek)

The chief geomorphological works based on geology and tectonics are: Prof. Danes's on the "Kras" (Kars) of Australia and Java, Absolon's on the Moravian "Kras " (Kars), Dědina's on north-eastern and Sokol's on western Bohemia, and Vitásek's on the upper Odra district. An interesting monograph on Czechoslovak earthquakes has been written by Koláček. The military geographical State Institute, founded at the beginning of the Republic, published a series of fine maps of our new state, both charts of large areas as well as special maps, I : 25,000 and $I: 75,000$.

\title{
Wheat Prices and Rainfall in Western Europe.
}

I $N$ an article on "Weather and Harvest Cycles" in the Economic Journal of December last Sir William Beveridge gave index-numbers showing the fluctuation of wheat prices in each year from 1500 to $\mathrm{r} 869$, and made a preliminary mathematical and arithmetical analysis of these figures with a view of discovering periodicity in the yield of harvests, which might be attributed to periodicity in the weather. In a paper read to the Royal Statistical Society on April 25, he has now given the results of a much fuller analysis, involving a test of the same figures by harmonic analysis, for the discovery of practically all possible periods between 2 and 84 years' length. The following is a summary of the paper.

The amplitudes for more than 300 trial periods altogether have been calculated for a sequence of about 300 years from I545 onwards, while for a number of these trial periods amplitudes have been calculated separately for the first $x_{50}$ years and for the second $x_{50}$ as well. These are shown on a periodogram from $q=\mathrm{r}_{50}(2$ years) to $q=3.6(84$ years). Each of the apparent periods indicated by the periodogram is considered in the light of four tests of periodicity: namely, the test of intensity (that is to say, comparison of the actual amplitude with the expectancy); the test of changing signs (both the elements $a$ and $b$ being required by theory to change signs in the neighbourhood of a period); the test of continuity (that is to say, indicating the same period, with agreement of phase as well as length, in each half of the sequence); and the test of agreement with other records (that is to say, the discovery of a similar periodicity in rainfall, temperature, or some other meteorological element). Particular importance is attached to the third of thesethe test of continuity.

The results of this analysis are summarised in a table showing some 20 apparent periods ranging in length from $2 \cdot 2$ to 68 years. These are arranged in four groups :-

(I) Periods the reality and persistence of which is beyond doubt, strong evidence from the analysis of wheat prices being confirmed by close agreement of first-rate meteorological evidence. This group includes the period of $2 \cdot 200$ years discovered originally by Mr. C. E. P. Brooks, and later by Mr. J. Baxendell in rainfall; the period of $5 \cdot \mathrm{I}$ years discovered by Mr. J. Baxendell in wind and rainfall and by Capt. D. Brunt in Greenwich temperature; and the period of about 35 years discovered in 1890 by Dr. Brückner in temperature, rainfall, and barometric pressure.

(2) Periods strongly indicated by the wheat prices but for which meteorological confirmation is, at present, weaker or lacking. This group includes seven periods of $5.67 \mathrm{r}, 9.750,12.840,15.225$, I9.900 54.000 and 68.000 years. Most of these periods are relatively long, a fact which helps in explaining failure 
to demonstrate them hitherto in meteorological records. For most of them some meteorological parallel can in fact be found.

(3) Periods for which there is good, but not firstrate, evidence both in wheat prices and in meteorology. There are four of these with lengths of $3.4 \mathrm{I} 5$ years, $4.4 \mathrm{I} 5$ years (traced by $\mathrm{Mr}$. Baxendell in rainfall), 5.960 years (traced by various writers in barometric pressure), and 8.050 years (no doubt the same as the period to which Prof. H. L. Moore and others have directed attention).

(4) The fourth group includes periods, some of which no doubt have reality, but all of which present inconstancy of action, changes of phase or other puzzling features. These include periods of 2.735 , $5.423,7.417,12.050$ and 17.400 years in addition to the well-known eleven-year period of the sunspots, which reappears in wheat prices with much of its normal instability of character.

The large number of periods found is striking. On a priovi grounds, however, there is nothing really surprising in the suggestion of so many separate periodicities in the weather. Comparison between the weather cycles indicated by analysis of wheat prices from $I 550$ to $I 850$ and the actual rainfall in the ensuing 72 years, I85O to I92I, confirms the view that these periodicities are real and important. For the purpose of this comparison, II of the I3 cycles in the first three groups are combined by a simple graphic method, the lengths and phases taken being exactly those determined by harmonic analysis; the combined result is shown in a single " synthetic curve" and is compared with the rainfall at 24 stations in Western and Central Europe (i.e. roughly the same area as that covered by the wheat prices records). A very high measure of agreement appears between the synthetic curve derived from wheat prices before $\mathrm{x} 85^{\circ}$ and the rainfall as actually recorded after $185^{\circ}$.

In particular, the synthetic curve shows depressions foretelling lack of rain (which, in the area under review, is generally beneficial to wheat) at each of the markedly dry years in the past 70 , namely
I857, I864, I870, I874, I883-4, I887, I898, I904 r908-9, I92I. It shows peaks foretelling heavy rain in the rainy years $1852, I 866, I 872, I 876$ (for I877), I906, I912, I9I6. The only important discrepancies are the failure of the synthetic curve to show peaks for the rainy years, I860 and 1903 , and a depression for the somewhat local, though severe, drought of I893. In other words, the synthetic curve which, subject to certain reservations, could have been drawn in $185^{\circ}$, if then drawn, would have foretold nearly all the important droughts and rainy seasons of the next 70 years. The drought of r92I stands out quite remarkably well.

In view of the inevitable errors in the simple hypothesis upon which the synthetic curve has been constructed, the very large measure of agreement obtained in spite of these errors is all the more convincing as to the substantial correctness of the results of the analysis. The question whether definite periodicities in the weather exist and can be discovered, must now be answered in the affirmative.

The two most interesting questions of all must still be left unanswered. The first is, what will be the weather next year and in the following years. As to that no prophecy is made at all; rather, the opportunity is taken of definitely withdrawing anything which might have appeared like a prophecy in the earlier paper. The author is not prepared to say anything as to whether I923 will be wet or dry. The full mathematical analysis in many ways has confirmed the earlier conclusions, but in more important ways goes beyond them; the general result might be quite different. Trustworthy prophecy of general weather conditions on the basis of periodicities now demonstrated should become possible in the near future, but only after a far more elaborate investigation than it has yet been possible to make.

The second question is, as to the seat and the physical cause of the periods appearing in the weather. A further analysis of the economic data may be helpful in some directions, but for the most part, that is a question for astronomers and physicists and should be left for them to answer.

\section{The Teaching of Natural History in Schools. ${ }^{1}$}

PROF. HICKSON and the other distinguished zoologists who have drafted the memorandum referred to below are deeply and properly concerned at the general neglect of zoology as a school subject. They maintain that this science should serve as a means of introducing youth to many of the greatest problems of life, and they therefore express astonishment, which will be shared by many people, at the findings of the investigators of the Secondary School Examinaton Council on the subject of school natural history. This body, in a recently issued report, committed itself to the remarks that "very few of the candidates (for certain important school examinations) offer this subject (Natural History), and it seems very doubtful whether it is worth while to maintain it as qualifying for a Pass with Credit in Science."

The members proceeded to express the opinion that the principles of biological science can be better illustrated by means of botany. From this latter view the authors of the memorandum dissent vigorously, and although the arguments they use will not perhaps appeal to botanists, there can, we think, be

i "Memorandum on the Teaching of Natural History in Schools," prepared by the Zoology Organisation Committee at the request of the Committee of Section D, British Association, Edinburgh, I92x. no doubt that all fair-minded botanists will support their conclusion that the principles of biology cannot be taught without reference to the animal kingdom.

More is wanted, however, than vigorous protest against examiners' opinions. Zoology is a science of vast range and school time is already taken up with many subjects. It devolves on the teachers of zoology to show in detail the kind of zoological syllabus that can be put into operation in schools as a basis for zoological teaching. In the drafting of such a syllabus they would naturally consult those teachers who have succeeded in maintaining and popularising zoology in their schools. As a preliminary to such a useful piece of work it would be necessary for zoologists to make up their minds whether it would be better to give the school zoology mainly or exclusively a natural history bias, or to attempt to treat the subject experimentally. There are arguments in favour of either method, and it might be found possible to draft alternative courses. With carefully drawn detailed syllabuses to guide instructors, and with occasional University courses for teachers, it should not prove impossible to secure for natural history a place in the curriculum of every school. 